\title{
A PRODUÇÃO DE TEXTOS SOBRE O CAMPO MULTIPLICATIVO DE PROFESSORES QUE ENSINAM MATEMÁTICA: O PROCESSO DE ELABORAÇÃO E REALIZAÇÃO DE ATIVIDADES
}

\author{
Ulianne Damasceno Silva ${ }^{1}$; Ana Virginia de Almeida Luna ${ }^{2}$ \\ 1. Ulianne Damasceno Silva, Graduando em Licenciatura em Matemática, Universidade Estadual de Feira de \\ Santana, NEEMFS, e-mail: ulianne.damasceno@hotmail.com \\ 2. Ana Virginia de Almeida Luna, DEXA, Universidade Estadual de Feira de Santana, NEEMFS, e-mail: \\ avaluna@uefs.br
}

PALAVRAS-CHAVE: Formação de Professores; Textos Legítimos; Multiplicação; Divisão; Planejamento.

\section{INTRODUÇÃO}

Neste resumo apresentamos o resultado da análise do processo de elaboração e realização de atividade por dois professores do $8^{\circ}$ e $9^{\circ}$ ano dos anos finais do Ensino Fundamental, em uma formação colaborativa de professores.

As atividades foram desenvolvidas no contexto de formação de professores do projeto "As Estruturas Multiplicativas e a formação de professores que ensinam Matemática na Bahia" denominado PEM (Núcleo Universidade Estadual de Feira de Santana (UEFS-Feira)), financiado pela Fundação de Amparo à Pesquisa do Estado da Bahia, um estudo de investigação teórico-conceitual sobre o campo conceitual multiplicativo (multiplicação e divisão) e que prevê estudo com uma ação de formação de professores com produção de material educacional, projeto interinstitucional, com sede na Universidade Estadual de Santa Cruz.

Para a presente investigação, os dados foram coletados pelo Núcleo de Estudos em Educação Matemática de Feira de Santana (NEEMFS), um dos polos da pesquisa. Neste artigo são contempladas atividades para mobilização do campo multiplicativo por profissionais que atuam com o ensino de Matemática no Ensino Fundamental, do $1^{\circ}$ ao $9^{\circ}$ ano, estão envolvidos 20 professores, 417 alunos dos anos iniciais do ensino fundamental e 306 dos anos finais e três escolas na cidade. Os professores e as escolas integraram no projeto de forma voluntaria.

No presente estudo analisamos os textos produzidos pelos professores durante a formação do PEM, dando foco nas produções e nas realizações das atividades durante a formação, por meio de vídeos, falas e os planos. Sendo assim entendemos texto, em termos bernsteinianos, como qualquer forma de comunicação verbal, escrita ou gestual (BERNSTEIN, 2003). Consideramos o texto legítimo quando as suas significações se adequam ao contexto no qual foi produzido.

De acordo com Bernstein (2003), os princípios de classificação e enquadramento que regulam as práticas pedagógicas, a classificação diz respeito às regras de reconhecimento do que pode ser dito nesse contexto, e o enquadramento dirá respeito as regras de realização como pode ser dito. Na prática pedagógica, as regras de reconhecimento criam os meios que regulam os significados considerados pertinentes em cada contexto. Quanto às regras de realização, elas determinam como relacionar os significados e fazê-los públicos. Essas regras são necessárias para a produção do texto legítimo, pois regulam o modo de unir os significados para a produção de textos legítimos.

Sendo assim, para esse projeto levamos em consideração a relevância da formação de professores para o processo de ensino e aprendizagem dos estudantes, que teve como proposta a realizar uma pesquisa no espaço de formação sobre o campo multiplicativo (MAGINA ET AL, 2014; GITIRANA ET AL, 2014; SANTOS ET AL, 
2014 ), para isso identificamos que textos em relação as ideias do campo multiplicativo os professores que atuam nos anos finais do ensino fundamental da Educação Básica reconhecem e como realizam esses textos ao elaborarem no espaço de formação atividades para desenvolverem em suas respectivas salas de aula e analisamos os textos que reconheceram e como realizaram esses textos ao elaborarem no espaço de formação atividades para desenvolverem em suas respectivas salas de aula sobre o campo multiplicativo.

\section{METODOLOGIA}

O objetivo da pesquisa foi compreender que textos os professores que atuam nos anos finais do ensino fundamental da Educação Básica reconhecem e como realizam esses textos sobre o campo multiplicativo ao elaborarem no espaço de formação atividades para desenvolverem em suas respectivas salas de aula.

A pesquisa foi desenvolvida por meio de uma abordagem qualitativa (BOGDAN; BIKLEN, 1994), com o foco na formação dos professores dos anos finais do ensino fundamental que ensinam matemática. Para tanto, tivemos como base metodológica o modelo reflexão-planejamento-ação-reflexão desenvolvido por Sandra Magina.

Utilizamos o modelo metodológico da linguagem de descrição, que é uma descrição sociológica de Bernstein (2000), a qual envolve uma relação dialética entre a teoria e os dados empíricos, ou seja, entre essas duas linguagens a interna (teoria) e a externa (empiria). "A linguagem de descrição possibilita movimentos cíclicos, a saber: 1) parte da teoria para iluminar a empiria (...) 2) legitima que os dados empíricos podem ampliar o campo teórico". (LUNA; SANTANA; BORTOLOTI, 2018, p. 202)

Para nortear a metodologia do projeto, buscamos responder a pergunta da pesquisa, com o trabalho dividido em quatro momentos, a saber: 1) Levantamento de materiais didáticos que os professores utilizam para o ensino e aprendizagem do campo multiplicativo, para este momento foi feita uma entrevista em que as perguntas foram relacionadas a sala de aula, quantos anos lecionando, matérias utilizados nas aulas, conteúdos em que se tem mais aproximação e etc. 2) Materiais utilizados na formação de professores "As estruturas multiplicativas e a formação de professores que ensinam matemática na Bahia"; apresentação do material produzido pela pesquisa, questões que os alunos de cada escola respondeu, gráficos e desempenho dos alunos. 3) Produção de atividade do campo multiplicativo pelos professores na formação; os professores se reunião em grupos, por serie, para a elaboração dos planos 4) Textos produzidos durante a formação nas discussões no decorrer das observações.

Foram convidados alguns professores para participar da Formação do Projeto de Estruturas Multiplicativas (PEM), os mesmos teriam que lecionar na rede municipal de Feira de Santana. Assim o critério de escolha foi ser professor(a) dos anos finais do ensino fundamental, que participasse de todos os momentos da formação e que estivesse disponível para ser observado em sala de aula. Na formação só tiveram dois professores que lecionavam nos anos finais do ensino fundamental.

Selecionamos esses dois professores, Pedro e Ana, que atuavam respectivamente no $9^{\circ}$ e $8^{\circ}$ ano, em um turno, em uma escola pública localizada na periferia da cidade de Feira de Santana, no interior da Bahia, e que atendeu ao critério de escolha apresentado anteriormente. Estes nomes são fictícios, a fim de respeitar a privacidade dos professores. 


\section{ANÁLISE DOS DADOS}

A análise ocorreu com ênfase nos textos produzidos pelos professores antes e durante a formação, podendo acompanhar toda a trajetória de Pedro e Ana dentro do grupo.

Destacamos que, neste processo de análise, consideramos também as aproximações realizadas pelos professores na construção de seus textos, ou seja, os caminhos que os mesmos foram vivenciando, no processo, da elaboração e na realização das atividades, já que durante o processo Ana e Pedro demonstravam mudanças nas produções dos seus textos.

Sendo assim, analisamos os dados da pesquisa a partir de três categorias, a primeira refere-se a Produção de problemas para o planejamento, em que Ana e Pedro não tiveram dificuldade, inicialmente, em elaborar problemas para o plano, ainda que nesse momento a elaboração desses problemas não tenha sido com diversificação de repertórios. Os problemas produzidos foram com enunciados, como por exemplo: $U m$ caminhão de areia constrói três casas em 12 dias com três caminhões serão construídas quantas casas em 20 dias?

Depois de analisarem os textos produzidos por eles e reconhecer o que estava sendo dito, desenvolveram problemas de diversas maneiras passando a mobilizarem diversos repertórios. Como pode ser observado abaixo:

Situação 1: Lucas descobriu que a distância média da terra à lua é de $384400 \mathrm{~km}$. Para testar a sua habilidade de fazer conversões de unidade de medida, resolveu escrever esta distância em centímetro. Sabendo que ele fez corretamente a conversão, qual foi o valor encontrado por Lucas em notação científica?

Situação 3: Seu Pedro tem dois Filhos: Lucas e Matheus. O dobro da idade de Lucas subtraído de 15 é igual a 5. Somando 8 à idade de Matheus e multiplicando o resultado por 3 dá 84. Sendo assim, a idade de Matheus é:

(A) duas vezes maior que a idade de Lucas. (B) duas vezes menor que a idade de Lucas. (C)três vezes maior que a idade de Lucas. (D)três vezes menor que a idade de Lucas.

Neste sentido, a segunda categoria é a Atividade introdutória do planejamento, envolvendo diferentes ambientes de aprendizagem em que Pedro e Ana não conseguiam ainda produzir o texto legítimo no que diz respeito a essa parte introdutória, tendo em vista que não tinham aproximação com planejamentos dessa forma. No entanto, com as atividades propostas na formação foi possível observar indícios de mudanças desde o início da elaboração do planejamento desses ambientes, ou pelo menos, um envolvimento deles na discussão:

Pedro: Como vamos fazer esse planejamento?

Ana: Não, sei! Pois ainda estou perdida.

Neste momento foram disponibilizado alguns materiais (jogos de tabuleiro, baralhos, dominós, bingo, entre outros), para que os professores se inspirassem na elaboração dos planos.

Ana: Podemos utilizar o jogo "Meu número é" para introduzir o conteúdo.

Pedro: Me explica esse jogo?

Ana: Distribuiríamos essas cartas em toda a sala, cada aluno fica com uma carta, sendo que uma carta vai ter sempre uma resposta. Assim eles teriam que achar a carta que tem a resposta da sua.

Pedro: Mas de que maneira podemos elaborar problemas voltado para esse jogo?

Levando em consideração que o momento da elaboração de uma atividade introdutória no plano era algo desafiador para o professor, foi possível analisar que eles 
começaram a produzir textos sobre a multiplicação para a elaboração de atividades para o plano com mais autonomia, notamos um menos distanciamento deles com relação a esse tipo de proposta. Legitimando a cada planejamento os textos produzidos por eles e reconhecendo e realizando o que é dito e o como é dito.

Por fim a última categoria analisada foi a Discussão da atividade realizada, esses textos envolveram os momentos em que os professores socializaram em grupo como foi difícil elaborar os planos e como foi difícil desenvolver em sala. Levando em consideração a dificuldade dos alunos nas resoluções. E o quanto eles tiveram que fazer intervenção.

Figura 1. Recorte dos comentários do Professora Pedro

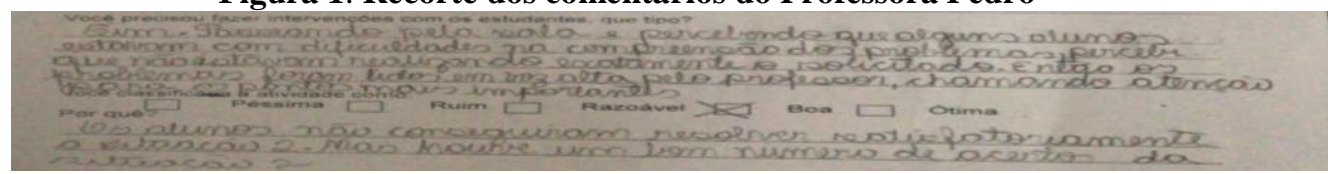

Fonte: Dados coletados pelo PEM, polo Feira de Santana (NEEMFS), em 2017.

Durante as realizações dos planejamentos Pedro deixou claro que tinha uma dificuldade em desenvolver em sala a parte introdutória dos planejamentos, por questão de tempo. Porém a professora Ana, conseguiu desenvolver um planejamento por completo (figura 2). No que diz respeito as demais atividades planejadas, pelo mesmo motivo de Pedro, Ana não conseguiu desenvolver a parte introdutória. Mas os dois deixaram evidenciado a importância de desenvolver a parte introdutória com diferentes ambientes de aprendizagens, além de situações-problema na prática pedagógica.

Figura 2. Jogo do Bingo com Multiplicação com Notação Científica da Professora Ana

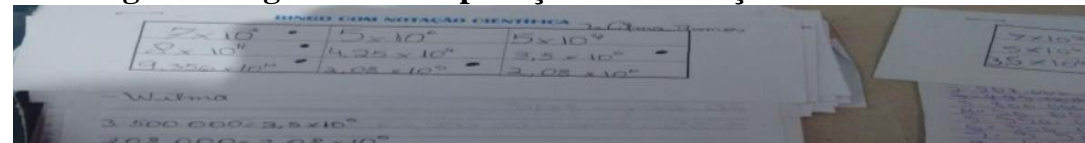

Fonte: Dados coletados pelo PEM, polo Feira de Santana (NEEMFS), em 2017.

Nesta pesquisa tivemos a oportunidade de identificar e analisar o processo de produção de textos ao elaborarem no espaço de formação atividades para desenvolverem em suas respectivas salas de aula. Como resultados encontramos o quanto é importante levar o professor a planejar diversos problemas em diferentes ambientes de aprendizagem e o quanto é desafiador para o mesmo reconhecer o que é dito e como deve ser dito na prática pedagógica sobre a multiplicação e a divisão. Sendo assim, a participação de contextos de formação com espaços de socializações de diferentes estudos realizados, mobilização de propostas variadas de planejamento e compartilhamento de atividades de realizadas pode favorecer ao professor produzir textos em sala mais desafiadores para os seus estudantes para o processo de ensino e aprendizagem.

\section{REFERÊNCIAS}

BERNSTEIN, B. Class, codes and Control, Vol. IV: The structuring of pedagogic discourse. Londres: Routledge, 2003.

BOGDAN, R.; BIKLEN, S. Investigação qualitativa em educação. Porto: Porto Editora, 1994. GITIRANA, V.; CAMPOS, T.M.M.; MAGINA, S.; SPINILLO, A. Repensando Multiplicação e Divisão: Contribuições da Teoria dos Campos Conceituais. 1. ed. São Paulo: PROEM, 2014. LUNA, A. V. A.; SANTANA, F. C. M.; MENDUNI-BORTOLOTI, R. D. A linguagem de descrição: uma possibilidade de fazer pesquisas no campo da educação matemática. Educação Matemática Pesquisa, 2018.

MAGINA, M.P.; SANTOS, A.S.; MERLINI. V.L. (2014). O raciocínio de estudantes do Ensino Fundamental na resolução de situações das estruturas multiplicativas. In: Ciênc. Educ., Bauru, v. 20, n. 2, p. 517-533.

SANTOS, A.; MERLINI, V.L.; MAGINA, S. M. P. ; SANTANA, E. . A noção de divisão para quem não aprendeu a divisão. Jornal Internacional de Estudos em Educação Matemática , v. 7, p. 38-64, 2014. 